\title{
SOBRE HUMILDAD Y PIEDAD: PARA UNA GENEALOGÍA DE LA MORAL URBANA MEDIEVAL
}

\author{
J. E. Ruiz Doménec
}

Estoy persuadido de una cosa: la vieja costumbre de pensar que la humildad y la piedad son dos principios inherentes a la conducta humana es sencillamente un error. El optimismo racionalista que mantenía estas ideas se desvanece por momentos. Poco a poco, los estudios históricos precisan con mayor exactitud el sentido de los conceptos sublunares, la aureola de los sueños y las fantasías o la dimensión de las asociaciones de ideas. Es preciso situar los sistemas de valores en su época. Pensar de cerca el desarrollo de una eticidad particular, aun a riesgo de no estar de acuerdo con las opiniones legalmente establecidas. Pero la historia social aspira a plantear los distintos grados de conciencia existentes en el pasado, lo que es una gran diferencia con respecto a nuestro legado más reciente ${ }^{1}$. Hoy no sólo vemos a los hombres mejorar o empeorar en cuanto a sus instintos o su moral, sino que vemos cómo esos instintos o esa moral varían conjuntamente con el ambiente social.

Por ello, $y$ antes que nada, quisiera determinar la campalidad del tema, es decir, fijar el carácter formal del campo de la humildad y la piedad. De este modo me coloco ante un panorama, cuya aprensión es syn-opsis, esto es, un espacio imaginario donde la reflexión permitirá inter alia hablar, plantear y responder sobre el dificilisimo asunto de qué cosa es la humildad

${ }^{1}$ Fr. Graus, Lebendige Vergangenheit. Uberlieferung im Mittelalter und in den Vorstellungen vom Mintelalıer, Köln-Wien 1975. 
y la piedad y su incidencia en la genealogía de la moral urbana de la Edad Media.

Inicialmente, la humildad y la piedad no se presentaron como un sacrificio religioso, sino como una disciplina moral que estimuló esa peculiar Weltanschauung del cristianismo primitivo. Desde Nicea en adelante los pensadores cristianos (fuertemente influidos por el estoicismo y por el carácter «popular» de sus principios religiosos) se levantaron contra el aura aristocrática de la tradición cultural clásica y en especial contra ese modo de vivir, que los griegos comprendian bajo el término de paideia ${ }^{2}$.

La humildad «popular» se identíficó con un Dios, Jesús de Nazareth, que anduvo sobre la tierra y participó activamente en la historia de los oprimidos, que estuvo implicado en los conflictos de la existencia y en las ambiguiedades de la vida, en contacto con prostitutas, ladrones y maleantes en general. La piedad «popular», por su parte, rechazó las religiones de los misterios e incluso la paradoja de la divinidad, a cambio de fortalecer la idea de milagro, esto es, un acontecimiento objetivo en sentido sobrenatural, único, que convirtiera a su Dios en el verdadero Dios. Así pues, el pueblo cristiano forjó una tendencia hacia la exclusión y el rechazo, peligrosa, pues el mensaje de Cristo estuvo en peligro de quedar anegado por la inmensa marejada de esta religión hostil a lo-otro, negadora de la fuerza personal o de las decisiones jerárquicas.

Luego llegaron los bárbaros y lo que les siguió. El cristianismo no pudo mantener los valores populares en el centro de su doctrina y discretamente los empujó hacia la periferia de su complejo doctrinal. Así, por ejemplo, en la Alta Edad Media, el topos hagiográfico creó un modelo de santo perfectamente adecuado a las virtudes aristocráticas de la época: un Adelsheilige, como dice Karl Bosl, donde se igualó el nobilis y el sanctus ${ }^{3}$. La herejia surgió a partir de entonces como una réplica por parte de los humildes ante esa forzada adaptación de la Iglesia a las condiciones sociales del momento. Se propagó,

${ }^{2}$ F. Lorrer, Severinus von Noricum. Legende und Historische Wirklichkeit. Untersuchungen zur phase des übergangs von Spätantiken zu Mittelalterlichen Denk und Lebensformen, Stuttgart 1976.

${ }^{3} \mathrm{~K}$. BosL, Der Adelsheilige, Idealtypus v. Wirklichkeit. Gesellschaftskritische Beiträge zu den Viten der bayrischen Stammesheiligen Emmeran, Rupert v. Korbinian. Speculum historiale, L. Spörl Geb., Freiburg 1965, pp. 167-187. Véase también el importante libro de E. Graus, Volk, Herrscher und Heiliger im Reich der Merowinger. Studien zur Hagiographie der Merowingerzeit, Praha 1965. 
especialmente con la llegada del milenio, insistiendo en que la humildad y la piedad eran los principios básicos de la religión. Los agentes impulsores de la subversión eran hombres cultos, conocedores de las Escrituras, expertos en las controversias doctrinales, nostálgicos del cristianismo primitivo. La Iglesia persiguió a los herejes no tanto por el contenido de su doctrina (con la que parcialmente estaba de acuerdo), sino por el uso social que se hacia de ella. El pueblo soñaba con liberarse de la tirania ideológica, transformar estos santos nobles en «confesores», salir para siempre del "salvajismo», de la magia y el misterio que rodeaba en cierto modo las prácticas religiosas de la época. La erupción de la herejía significó que el cristianismo primitivo se mantenía vivo en las masas de la población y que luchaba por imponer sus ideas, aunque precipitada y atropelladamente. Las hogueras no calmaron los espiritus ni ahogaron las esperanzas. La idea continuó, aunque con serias dificultades ${ }^{4}$.

Los herejes tuvieron que luchar también con los grupos dominantes, con los señores feudales, carentes de sensibilidad ante los principios de la humíldad y la piedad. Los domini et seniores constataron que estas ideas destruian el equilibrio funcional de su ejercicio político. Los milites aplicaron estas enseñanzas al control de la producción y del distrito. La actitud de los obispos en las asambleas de Paz y Tregua de Dios se consumió en la añoranza del pasado o en la desilusión de ver cómo sus proclamas caían en el vacío. Nadie, en la buena sociedad de los siglos XI y XII, creyó en la humildad y la piedad, pues ambas eran extrañas a los sistemas de valores y a las normas estructurales que rigieron el orden social $y$ político de la feudalidad europea.

La larga batalla del cristianismo contra bárbaros y feudales terminó con la derrota de estos últimos. Las primeras grietas se perciben tras la bruma de las creaciones imaginarias pasado el 1150; luego se extiende como una mancha de aceite y alcanza plena configuración teórica y práctica al filo de 1200 . La humildad y la piedad habitan a partir de entonces en alojamientos adecuados a su forma, en medio de una sociedad en convulsión, temerosa ante los vientos de herejía, agitada por

${ }^{4} \mathrm{G}$. DuBY. Les trois ordres ou l'imaginaire du feodalisme. Paris 1978 , pp. 163-168. Véase E: WERnER, Häresie und Gesellschaft im II. Jahrhunderi, Akademie Verlag, Berlin 1975. 
la profunda riqueza acumulada, móvil por la eficaz apertura al mundo, perpleja por la invasión de novedades culturales procedentes de otras civilizaciones. No en vano a principios del siglo XIII la ideología católica se endureció y se volvió sobria. El gótico fue el enemigo número uno del misterio del pasado (el bárbaro o el feudal). Una ideología «populista» relanzó el viejo sueño del cristianismo primitivo - una religión asentada en un gran milagro «objetivo»: la universalidad de la conciencia moral.

No veamos esta gran convulsión en el cuerpo social de la cristiandad latina como si los hombres añorasen una experiencia nueva. La buena sociedad de entonces estaba sobresaturada y cansada de resistir el empuje doctrinal de la Iglesia. Se rindió a sus fórmulas, aun a sabiendas que aquello deslizaria a todos hacia un abismo de difícil salida. Por eso nadie se sintió sobrecogido cuando; en medio de la marea cultural, social y politica de finales del siglo XII (entre 1160-1180), apareció la definición de una nueva subjetividad ${ }^{5}$. El cansancio hizo mella en las conciencias, el reto fue absurdo; y en este cansancio y agotamiento aparecieron las primeras formulaciones de este agudo cambio que indujo a adoptar la humildad y la piedad como principios fundamentales del comportamiento humano.

Asi fue en efecto. A partir de esos años la humanidad se hizo «pobre»: entregó parte de su alegría a cambio de la opulencia que surgía de una economía del beneficio. El derroche, que era una costumbre feudal, se convirtió en un empeño dramático, reservado tan sólo a algunos nostálgicos del viejo sistema. La evolución de la economía monetaria condujo a una revalorización sin precedentes de la austeridad y del ahorro ${ }^{6}$. Lo demás vino por añadidura. Pues con esta cobertura era lógico que en muy poco tiempo aparecieran como principios fundamentales de la buena sociedad la humildad y la piedad: dos viejas categorias (spopulares) que sobrevivieron a la Barbarie y a la Feudalidad. Tal vez en esta resistencia se encuentra la clave de su profunda eclosión en medio de los truenos de la guerra y de la represión.

Fijémonos en un bello ejemplo de lo que vengo diciendo: se trata de la completa definición de tales principios según apa-

${ }^{5}$ Cf. mi libro La caballeria o la imagen conesana del mundo, Génova 1984.

${ }^{6}$ L. K. LiTtLE, Religious Povery and the Profit Economy in Medieval Europe, Elek, Londres 1978. 
recen en una de esas novelas de ambiente artúrico escrita en prosa hacia la tercera o la cuarta década del siglo XIII, y que conocemos como la Queste del Saint Graal ${ }^{7}$. En medio de un relato lleno de misticismo cisterciense y de religiosidad «popularn, un caballero - pero no el principal ni el elegido, sino uno de los parientes de menor rango- llamado Boores de Gaunes se encuentra en su larga errancia en busca del sentido del mundo a un hombre vestuz de robe de religión. Y hablan entre sí. El texto de esta conversación dice asi' 8 :

Or dit li contes que quant Boorz se fu partiz de Lancelot si come li contes a devisé, qu'il chevaucha jusq'a hore de none. Lors ateint un home de grant aage qui ert vestuz de robe de religion et chevauchoit un asne, ne n'avoit o lui serjant ne vaslet ne compaignie mule. Boorz le salue et li dist: "Sire, Diex vos conduie'n Et cil le resgarde et conoist qu'il est chevaliers erranz, si li respont que Diex le conseut. Lors demande Boorz dont il vient einsi seuls. "Je vieng, fet il, de visiter un mien serjant qui est malades, qui me souloit aler en mes aferes. Et vos, qui estes et quel part alez vos? sui, fet-il, uns chevaliers erranz qui suiz meuz en une queste dont je voldroie molt que Notre Sires me conseiliast. Car ce est la plus haute queste qui onques fust comenciee, ce est la Queste dou Saint Graal, ou cil avra tant honor, qui a fin la porra mener, que cuer d'ome mortel nel porroit penser.,

- "Certes, fet li preudons, vos dites verité, honor i avra il grant, et ce n'iert mie de merveille, car il ert li plus loiax serjanz et li plus verais de toute la Queste. II n'entrera pas en ceste Queste vil ne conchié ne ort, come sont li desloial pecheor qui $i$ sont entré sanz amendement de vie: car ce est li services meesme Nostre Seignor. Or resgardez come il sont fol. Il sevent bien, et maintes foiz lont oï dire, que mus ne puet a son Créator venir sïl n'i vient par la porte de neteé, ce est par confession; car nus ne puet estre mondez ne netoiez se veraie confession nel visite: par la confession en oste len lanemi. Car quant li chevaliers, ou ti hons quel qu'il soit, peche mortelment, il recoit l'anemi et manjue, mes garder ne s'en puet qu'il ne soit toz diz o lui. Et quant il $i$ a esté dis anz ou vint, ou combien de terme que ce soit, et il vient a confession, il le vonche hors et le giete de son cors et herberge autre dont il a greig. nor honor, ce est Jhesucrist. Si a presté longuement a la chevalerie

${ }^{7}$ Sus circunstancias y ambiente en R. H. BLOCH, Etymologies and Genealogies. A Literary Anthropology of the French Middle Ages, Londres-Chicago 1983.

8 Utilizaré la edición de Albert Pauphilet, París 1949, pp. 162-164. La traducción es de C. Alvar, Editora Nacional, Madrid 1978. 
terriane la viande del cors. Or s'est eslargiz et adouciz plus apertement qu'il ne seut. Car il lor a prestee la viande del Saint Graal, qui est repessement a l'ame et sostenement dou cors. Iceste viande est la douce viande dont il les a repeuz et dont il sostint si longuement le pueple Israhel es deserz. Einsi s'est ore esiargiz envers els, car ii lor promet or la ou il souloient prendre plom. Mes tout ausi come la viande terriane s'est changiee a la celestiel, tout ausi convient il que cil qui Jusqu'a cest terme ont esté terrien, ce est a dire que cil qui jusqu'a cel terme ont esté pecheor, soient changié de terien en celestiel, et lessent lor pechié et lor ordure et viegnent a confession et a repentance, et deviegnent chevalier Jhesucrist et portent son escu, ce est pacience et humilité. Car autre escu ne porta il contre l'anemi, quant il le vainqui en la Croiz ou il soffri mort por ses chevaliers oster de la mort d'enfer et dou servage ou il estoient. Par cele porte, qui est apelee confession, samz quoi mus ne puet venir a Jhesucrist, covient entrer en ceste Queste et muer lestre de chascun et changier, contre la viande qui changiee lor est. Et qui part autre porte voldra entrer, ce est a dire qui se travaillera granment sanz aler a confession premierement, il $n^{\prime}$ t trovera ja chose que il quiere, ainz s'en revendra sans taster et sans gouster de cele viande qui promise for est. Et encor lor avendra il autre chose. Car por ce qu'il se metront en leu de chevaliers celestiex et si nel seront mie, ce est qu'il se tendront a compaignon de la Queste et si nel seront pas, ains seront ort et mauvés plus que jel ne porroie penser, et en charra li uns en avoutire, li autres en fornicacion et li autre en homicide. Et einsi seront gabé et escharni par to pechié et par engin de deable, qu'il s'en revendront a cort sanz riens trover, fors ce que li anemis done de lui servir, ce est honte et deshonor, dont il avront a plenté ainz qu'il reviegnent mes arrieres. Sire chevaliers, tot ce vos ai je dit por ce que vos estes meuz en la Queste dou Saint Graal. Car je ne loeroie en nule maniere que vos vos traveillissiez plus en ceste Queste, se vos n'estiez tiex que vos en deussiez estre.»

- "Sire, fet Boorz, il me semble, a la raison que vos me dites, quill en seront tuit compaignon s'en elx ne remaint, car sanz faille il m'est avis que en si haut servise come cist est, qui est meesme servise Jhesucrist, ne doit nus entrer fors par confession. Et qui autrement i entrera, je ne cuit mie qu'il li puisse bien chaoir, qu'il soit trouverres de si haute trouveure come ceste est.»- "Vos dites voir, fet li preudons."

Lors li demande Boorz sill est prestres. "Oil, fet il." - "Dont vos requier je, fet Boorz, ou nom de sainte charité, que vos me conseilliez com li peres doit conseillier le fil, ce est li pechierres qui vient a confession; car li prestres est en leu de Jhesucrist, qui est peres a toz cax qui en lui croient. Si vos pri que vos me conseilliez au profit de l'ame et a l'ennor de chevalerie.n - "A non Dieu, fet li presidons, vos me requerez grant chose. Et se je de ce vos failloie, 
et puis chaïssiez en pechié mortel ou en error, vos m'en porriez apeler au grant jor espoantable devant la face Jhesucrist. Por ce vos conseillerai au mielz que je porré,n Lors li demande coment il a non, et il dit qu'il a non Boort de Gaunes et fu filz le roi Boort, et cousins monseignor Lancelot del Lac.

Cuenta la historia que cuando Boores se separó de Lanzarote, tal como ha narrado anteriormente, cabalgó hasta la hora de nona: entonces encontró un hombre de mucha edad, vestido con ropa de religión y que cabalgaba sobre un asno; no llevaba ni sirviente, ni criado, ni ninguna compañía. Boores le saludó y le dijo: "Señor, Dios os guíe.» Aquél le mira y se da cuenta de que es un caballero errante; le responde que Dios le conduzca; entonces Boores le pregunta que de dónde viene así de solo. "Vengo - le responde - de visitar a un criado mío que está enfermo y que solía llevarme los negocios. Y vos, ¿quién sois? ¿A dónde vais?» "Soy - le contesta- un caballero andante, que estoy metido en una Demanda, en la que querría que Nuestro Señor me aconsejara, pues es la más elevada búsqueda que nunca fue comenzada: la Demanda del Santo Graal. Quien pueda llegar al final alcanzará en ella tal honor como no podria pensar corazón de hombre mortal.»

«Ciertamente - contesta el anciano - decís verdad: tendrá gran honor y no debe maravillar, pues tal será el más leal servidor y el más verdadero de toda la Demanda, ya que habrá entrado en ella ni vil, ni sucio, ni manchado, como están los desleales caballeros que la han iniciado sin arrepentirse de su vida. Asi ha de ser el servicio mismo de Nuestro Señor. Ahora mirad cómo están de locos: saben bien, pues muchas veces lo han oído decir, que nadie puede acercarse a su Creador si no es llevado por la limpieza, que es la confesión, y nadie puede estar limpio, ni puro, si no lleva a cabo verdadera confesión y por la confesión se arroja al Enemigo; cuando un caballero o un hombre, cualquiera que sea, peca mortalmente, recibe al Enemigo y le da alojamiento y no puede evitar que todo el día esté con él y cuando ha estado diez o veinte años o el tiempo que sea y vuelve a confesarse, lo arroja fuera y lo echa de su cuerpo albergando a otro, con el que alcanza honra: Jesucristo, que durante mucho tiempo ha prestado a la caballería terrena el alimento de su cuerpo, pero ahora se ha mostrado más generoso y más dulce que nunca, pues les ha ofrecido el alimento del Santo Graal, que es comida para el alma y sustento para el cuerpo. Este alimento es el dulce manjar con que alimentó y sostuvo durante tanto tiempo al pueblo de Israel en el desierto y, ahora, se ha mostrado asi de generoso con ellos pues les promete oro donde solían tomar plomo. Pero del mismo modo que ha cambiado la comida terrena por la celes- 
tial, conviene que ellos, que hasta ahora han sido terrenales, o con otras palabras, que hasta ahora han sido pecadores, se cambien de terrenales a celestiales y dejen sus pecados y sus inmundicias y vengan a la confesión y al arrepentimiento, que se conviertan en caballeros de Jesucristo y lleven su escudo, que es la paciencia y la humildad, pues El no llevó otro contra su Enemigo cuando lo venció en la Cruz, donde sufrió la muerte por quitar a sus caballeros de la muerte del infierno y de la esclavitud en la que estaban. Por esa puerta, que se llama la confesión, sin la cual nadie puede llegar a Jesucristo, conviene que entren en esta Demanda y que cambie la condición de cada uno, como la comida les ha sido cambiada, y quien quiera entrar por otra puerta, es decir, quien se esfuerce grandemente sin ir a la confesión, primero no encontrará nada de lo que busca, sino que volverá sin probar y sin catar esta comida que les ha sido prometida y además, les sucederá otra cosa, puesto que entrarán en lugar de caballeros celestiales y no lo serán, y se tendrán por compañeros de la Demanda y no lo serán, sino que estarán sucios y serán malvados, más de lo que pudiera pensarse: uno caerá en adulterio, otro en fornicación, otro en homicidio, y así serán humillados y escarnecidos por su pecado y por culpa del diablo, ya que volverán a la corte sin encontrar nada más que lo que el Enemigo da por su servicio: vergujenza y deshonor, de los que tendrán en abundancia si no se vuelven atrás. Señor caballero, todo esto os lo he dicho porque vos habéis entrado en esta Demanda del Santo Graal y yo no permitiria, de ninguna forma, que continuarais en ella si no estuvieras tal como se debe estar.»

«Señor - responde Boores- me parece, según lo que me decís, que no serán compañeros todos, aunque lo desean, pues sin falta me parece que en un servicio tan alto como éste, que es el servicio mismo de Jesucristo, no debe entrar ninguno si no es a través de la confesión; el que entre de otra forma, no creo que pueda llegar a bien y que encuentre un hallazgo tan alto como éste.» «Decís verdad», le contesta el hombre bueno.

Entonces le pregunta Boores si es sacerdote. «Si», le contesta. "Os pido - dice Boores - en nombre de la Santa Caridad que me aconsejéis, como el padre debe aconsejar al hijo, que es el pecador que viene a la confesión, pues el sacerdote está en lugar de Jesucristo, que es el padre de todos aquellos que creen en El: os ruego que me aconsejéis en provecho del alma y por honor de la caballería." «Por el nombre de Dios - dice el anciano - me requerís para una gran cosa; si yo me equivocara y después cayerais en pecado mortal o error, me podriais acusar ante el rostro de Jesucristo el gran día espantoso, y por eso os aconsejaré lo mejor que pueda.» Entonces le pregunta 
cómo se llama y le dice que se llama Boores de Gaunes y que fue hijo del rey Boores y primo de Lanzarote del Lago.

Este diálogo entre un caballero y un clérigo constituye el lugar estratégico donde mejor se define la ideología del momento: un exemplum, según la costumbre de los predicadores de aquella época, que se convierte al mismo tiempo en una metáfora y en un cuerpo de representaciones: conjunción del orden político y el económico. Una polarización de la conducta humana: o la Queste de la empresa celestial o la caida en el pecado, la alienación, la descreencia (que induce al adulterio, a la fornicación, al homicidio). Polarización que conjuga en un mismo cuerpo social el pasado y el futuro. Por eso, la gran cuestión pendiente aparece a continuación, cuando después de un leve ejercicio de identificación por parte del caballero (identificación aún a la manera feudal, pues tiene en cuenta la filiación y la alianza: «hijo del rey Boores y primo de Lancelot del Lago»), el clérigo le contesta:

Quant li preudons ot ceste parole, si respont: "Certes, Boort, se la parole de l'Evangile ert en vos sauvee, vos seriez bons chevaliers et verais. Car, si com Nostre Sires dit: "Li "bons arbres fet le bon fruitn, vos devez estre bons par droiture, car vos estes le fruit del tres bon arbre. Car vostre peres, li rois Boors, fu uns des meillors homes que je onques veisse, rois piteus et humbles; et vostre mere, la reine Eveine, fu une des meillors dames que je veisse pieça. Cil dui furent un sol arbre et une meisme char par conjonction de mariage. Et puis que vos en estes fruit vos devriez estre bons quant li arbre furent bon."

Cuando el buen hombre oye estas palabras responde: «Verdaderamente, Boores, si la palabra del Evangelio se cumpliera en vos, vos seríais un caballero bueno y auténtico, pues asi como Nuestro Señor dijo: "El buen árbol da buen fruto", vos debéis ser bueno por justicia, pues sois el fruto de un árbol muy bueno, pues vuestro padre el rey Boores fue uno de los mejores hombres que yo haya conocido nunca, rey piadoso $y$ humilde, y vuestra madre la reina Eveina fue una de las mejores damas que he visto en todo tiempo; ellos dos fueron un solo árbol y una misma carne por la unión del matrimonio, y ya que vos fuisteis el fruto, deberiais ser bueno, pues lo fueron los árboles.» 
Tres niveles de análisis pueden ser tomados en consideración en este texto:

1. La conexión entre el orden familiar y el orden moral. El texto establece como valor universal un fenómeno que acababa de instalarse en el suelo europeo. La conjunción y la unión indisoluble de los progenitores del caballero errante en un santo matrimonio, bendecido por la Iglesia. Este nuevo ideal evoca a la vez la exigencia eclesiástica de controlar la institución matrimonial como la de implantar en el seno de la sociedad (especialmente la urbana) unos principios filativos de carácter intensivo, frente a las normas de la alianza feudal en trance de desaparición. Fenómenos ambos que aseguran la alteridad social promovida por el proceso económico.

2. La sistemática inscripción en la vida individual de una serie de nuevos códigos cuya significación tendrá implicaciones saciales. Parte de una toma de conciencia de culpabilidad por parte de los jóvenes caballeros errantes, que son empujados a abandonar su tipo de vida para formar parte de los grupos dirigentes del mundo urbano. La memoria de los antepasados es deteriorada y subvertida: el recuerdo del Padre del joven caballero representa un implexe germinal, para hablar como Deleuze, donde el complejo de Edipo se desplaza por consideración del rol social y moral del Padre: aquí los nuevos valores de origen «popular» marcaron la diferencia con el pasado, pues ese Padre fue piadoso $y$ humilde.

3. La valoración directa y abierta del mensaje cristiano inscrito en los Evangelios. El hombre de la Iglesia usa el Evangelio de un modo condicionado; se interesa no por la veracidad del mensaje (cosa que está fuera de toda duda, ¿lo está?), sino por la capacidad de saberlo interpretar por parte de los laicos. Las dudas del momento pesaron lo suyo en esta dimensión consecutiva de la moral a punto de implantarse en las tierras de Occidente. En el Evangelio se lee con claridad la razón de esa moral.

El cristianismo volvió a sus orígenes: combatió a los herejes y luchó contra la resistencia de los últimos feudales. La Iglesia se endureció y adoptó la forma monárquica, totalitaria, alrede- 
dor de la sede de San Pedro y de un papa, Inocencio III. Los planteamientos eclesiásticos respondieron a las modas del momento y subrayaron la postura oficial - fijada con énfasis en el IV Concilio de Letrán de 1215 - ante los misterios de la revelación". Reacción ante el simbolismo y el naturalismo. En el programa conciliar y reformador aparece en primer término la necesidad de imponer la humildad que permite al hombre reconocer sus propios limites y evitar rebajar el creer a un simple conocer. Limites que en relación a Dios exigen sumisión y adoración, es decir, piedad.

Históricamente, la conjunción de estos tres aspectos desarrollados en el discurso del clérigo al caballero errante, dieron lugar a la creación de nuevas formas de expresión religiosa que alcanzaron plena maduración en los núcleos urbanos. Los nuevos estilos propuestos por los mendicantes cautivaron a los ricos de las ciudades y a los grandes burgueses. Estos proyectos incluian una justificación ética del trabajo ejercido en las ciudades, asi como una extensión de la humildad y la piedad como valores de conciencia universal. Aspectos ambos que a través de la práctica matrimonial precipitaron la evolución del cristianismo hacia lo que llegó a ser en siglos venideros.

Este es el centro de la problemática que deseaba exponer. Si se toman los dos valores, humildad y piedad, con arreglo a su contenido y a su eficacia ideológica para imponer un nuevo tipo de subjetividad, la imagen que ofrecen es, desde un punto de vista formal, la de un conflicto de dos eticidades, y desde el plano del contenido, la de una dualidad de la ley divina y la ley humana. Los jóvenes salen de la esencia inconsciente, del espiritu familiar, y se adaptan a la individualidad de la comunidad social regida por los principios de la Iglesia. La desigualdad del nacimiento, de los origenes, como diferencia natural (racial o étnica), no tiene significación alguna para ellos, que entran a formar parte de la esencia ética del mundo eclesiástico. Los poemas didácticos, los sermones en lengua vulgar, la novela llamada realista, crean un estado de opinión favorable a la elisión de todo resentimiento de los vástagos de las grandes familias aristocráticas ante el hecho evidente de la destrucción de los sistemas de valores de sus padres por parte de este movimiento espiritual. El recuerdo familiar quedó sepultado por

${ }^{9} \mathrm{Cf}$. J. BALDWIN, Masters, Princes and Merchands. The social views of Peter the Chanter and his circie, Princenton, N.J. 1970, pp. 315 ss. 
las nuevas ansias morales, fruto del desarrollo de la economía monetaria y de la presión social surgida en el mundo urbano. El olvido motivó la creación de un orden político, forjado alrededor de una eticidad concreta, cristiana, inspirada en la labor de los obispos ${ }^{10}$.

A principios del siglo XIII una cosa estaba bastante clara: el mundo urbano y la monarquía sólo subsistirian mediante el quebrantamiento de la memoria familiar y la disolución de la autoconciencia doméstica en la conciencia universal promovida por los clérigos y los frailes mendicantes para alterar los principios privados de la razón política de los feudales. De este modo, el mensaje cristiano, al pensar en lo universal, se burló de la altivez de las casas aristocráticas y despreció su entusiasmo festivo. Con urgencia aparecieron normativas que pusieron fin a cualquier acto cultural $-y$ cultual - que fuese sospechoso. Todo lo sospechoso era denunciado por el rumor público, perseguido, detenido, aniquilado. Y lo más digno de recelo por entonces fue, naturalmente, la falta de humildad y de piedad.

La ruptura con el pasado se consumó en cuatro niveles (que eliden definitivamente las cuatro relaciones del átomo del parentesco hacia 1240): el hijo se levantó y se rebeló contra el Padre (o mejor aún, contra la memoria y el nombre del Padre); aquí el ejemplo de Francesco pesó lo suyo, pues este hombre, venerado como un santo, se convirtió en el paradigma de la humildad y la piedad cristiana. Luego, el hermano miró con otros ojos a su hermana. Las mujeres alcanzaron un valor diferente en este momento; sensibles a las predicaciones, comenzaron a preocuparse por su espiritualidad y se levantaron contra su destino de ser simplemente un «objeto» de intercambio matrimonial. Las mujeres, al menos las ricas, tuvieron mucho que decir en el orden social que se avecinaba. La fraternidad espiritual pesó más que la de la sangre. En tercer lugar, el marido desconfió abiertamente de la feminidad de su esposa, a quien despreciaba. Los hombres prefirieron contraer matrimonio con mujeres de rango inferior, como aconsejaba Andrés el Capellán, nada altivas y carentes del carisma que las

10 Para la naturaleza de esta ruptura con la memoria feudal, véase mi libro La memoria de los feudales, Argot, Barcelona 1984. 
hacia difíciles e indómitas. Finalmente, los jóvenes no quisieron saber nada de los siblings de su madre; el tío materno perdió su importante rol social y político y quedó reducido a ser un pariente de segundo orden. En suma, la nueva comunidad se mantuvo gracias a una fuerte hostilidad ante el espíritu feudal $y$ al ejercicio político de la (sprivacidad».

El abismo se acrecentó. La humildad y la piedad fueron los agentes de la represión surgida a principios del siglo XIII y conducida por las órdenes mendicantes en el interior del espacio urbano contra cualquier tipo de disidentes. La persecución fue atroz; la tolerancia casi inexistente; la inquisición temible y peligrosa; la conversión rápida, tibia e insegura.

Pero en cualquier caso, el declinar de la sustancia ética de la feudalidad y su transición a otra figura se halló determinada por el hecho de que la conciencia moral se orientó hacia un tipo de ley «popular», inquisitiva, forjada en el análisis y la indagación. La consecuencia más espectacular de todo ello fue el deslizamiento de los jóvenes de buena familia hacia las actividades productivas (pero no al trabajo, sino al comercio, la banca, la jurisprudencia, el notariado, la enseñanza universitaria, etc.). Esta realidad que negaba de hecho el ocium caballeresco (y, naturalmente, el feudal) patentizó el germen de una nueva sociedad y un nuevo sistema de valores en trance de instalarse definitivamente en el suelo europeo. En virtud de tales decisiones, aparecieron renovadas formas de expresión: hablar, discutir, negociar, escribir, persuadir, convencer, se convirtieron en los pilares del espiritu de empresa ${ }^{11}$.

La humildad y la piedad finalmente encauzaron la universalidad formal de la moral cristiana, pues los nuevos modos de comportamiento no son intrínsecos a la naturaleza humana, sino que son la reciedumbre simple de la subjetividad forjada al calor de la doctrina eclesiástica. Y por esta razón consiguió separar eficazmente a los individuos de la sangre de su familia y de la devoción al pasado de su linaje. Los cives urbanos en un momento determinado de su evolución histórica (ipero cuándo en realidad?) no quisieron operar en solitario ni seguir ligados a las viejas estructuras de parentesco feudales, sino extender ese espiritu de empresa, humilde y piadoso, al ejercicio

11 Cf. K. L. LITTLE, op. cit. 
de la función política y económica. En pocas palabras, aspiraron a tener un socius. Esta inclinación hacia una universalidad abstracta (abstracta porque su contenido es en sí mismo rígido y porque el escrito sustituye a la palabra y al gesto) forjó la diferencia social, prueba taxativa de la alteridad producida por el conflicto ético. Los contratos de accomendacio y societas se convirtieron en el vehículo de un modelo social y económico, político y cultural, que condujo a la Compagna y a través de ella al capitalismo ${ }^{12}$.

Para concluir: humildad y piedad son los pilares de la moral urbana a partir del siglo XIII. Estos dos principios éticos de la cristiandad, forjados en un desprendimiento de las relaciones familiares, inspiraron la labor de los hombres en la ciudad medieval y su específico Beruf ${ }^{13}$. Los cives y burgueses, altivos, orgullosos de su función, se sintieron libres y responsables, singulares y únicos, es decir, se sintieron personas. Pero personas solitarias que se enfrentaban legalmente a un mundo hostil, extenso, ilimitado, peligroso pero inmensamente rico y lleno de posibilidades. Un mundo que exigía ser conquistado. El espíritu de empresa articuló estos valores surgidos de un movimiento doctrinal y ofreció al pueblo laico la ilusión de que la eticidad cristiana era el símbolo de una religión interior, cuyo santuario era el corazón del hombre. El habitante de las ciudades, suma y compendio de todas las virtudes cristianas, se comportó de acuerdo a lo que representaba junto a sus otros socios y amigos. En muchas ocasiones toda la población de una ciudad se reunía en una inmensa representación colectiva para dar testimonio de un acto humilde y piadoso. El teatro generalizó estos gustos y mostró las potencias del alma contenidas en la nueva moral, lo que hizo posible el goce de toda una comunidad, aunque también en muchas ocasiones dio lugar a un desmedido frenesi ${ }^{14}$. Al vulgarizarse, la humildad y la piedad se hicieron doctrinales y favorecieron el fana-

12 Para un caso concreto, el de Génova, cf. G. Pistarino, "Comune, "Compagna" e Commonwealth nel Medioevo Genovesen, La Storia dei Genovesi, 1982.

${ }^{13} \mathrm{E}$. MASCHKE, «Die Unterschichten der mittelalterlichen Städte. Deutschland", Gesellschaftliche Unterschichten in den sïdwestdeutschen Städtien, 1967. K. BosL, Die Grundlagen der modernen Gesellschaft im Mittelalter, Stuttgart 1973, vol. II, pp. 301 ss.

${ }_{14}$ Aspectos que analiza con precisión J. Delumeau, La peur en Occident, Paris 1978. 
tísmo religioso hasta el punto que, en la cultura urbana de los siglos XIV y XV, la conciencia moral desarrollada por ellas no se consiguió mediante una insistencia en los valores de la persona, sino mediante una reafirmación del extrañamiento del individuo en el espacio del más allá. Esta inevitable caida puso de manifiesto a las claras los riesgos de la aplicación de la humildad y la piedad como principios del comportamiento humano, pues el conflicto entre las dos eticidades y la dualidad entre las dos leyes permaneció durante siglos y empujó a la cultura urbana al desvario en un movimiento que pasando por el miedo terminó en una auténtica neurosis. 